In conclusion, it may be said that, while the sum of the percentages of the different constituents in many feeding stuffs does not equal exactly roo per cent., the results are as close as could be expected with the present methods of analysis. In addition to the uncertainties of some of the analytical steps just pointed out, it should also be noted that the factors used for the calculation of protein and pentosans are more or less of an arbitrary nature, and cannot be considered absolute in the case of any particular feeding material. In view of this, and our present incomplete knowledge of many of the various proximate constituents of feeding materials, the exactness attainable in some other departments of analytical chemistry is not at present to be hoped for.

\title{
CATALYSIS IN CONCENTRATED SOLUTIONS.
}

\author{
BY J. M. CRAFts.
}

Received March 8, sgor.

HE study of the catalytic action of acids in very dilute
solutions has led to the discovery of a number of simple relations between ionic dissociation, chemical affinity, and electrical conductivity, and the conclusion is universally accepted that the active agent is the hydrogen ion. The ratio of the velocity of the reaction to the concentration of the catalysor is nearly constant in dilute solutions of strong acids, but when ionic dissociation is diminished by increasing concentration, or in the case of weak acids by the presence of bodies which reduce the concentration of hydrogen ions, the ratio of velocity to concentration diminishes; a small acceleration has, however, been observed when certain salts are added to the solutions of strong acids. Most of the subjects for experiments, such as the decomposition of esters, the inversion of sugar, etc., do not admit of the employment of very concentrated acid solutions, because the catalysor would then enter into the reaction, forming by-products.

It seemed interesting to study the hydrolysis of the sulphonic acids by means of chlorhydric acid and other strong acids, because here the reaction is catalytic in the serse that it is induced by the presence of a strong acid which does not enter into the final products, nor does it even form intermediate products in the same evident way as in esterification by sulphuric acid, or in the oxidation of sulphurous acid through the medium of nitrous fumes, nor does the degree of concentration of the catalysing 
agent change the nature of the products, which are only sulphuric acid and hydrocarbon.

The results given below show that the rapidity of the reaction instead of being proportional to the concentration of the catalysor, rises to a thirty-fivefold greater rapidity when 38 per cent. chlorhydric acid solution is employed instead of 19 per cent., and a very remarkable result was obtained by adding to a 38 per cent. chlorhydric acid solution one-half its weight of zinc chloride, the rapidity of the reaction being then raised more than threefold.

It is thus apparent that increased concentration and other influences which must be supposed to diminish ionic dissociation, promote to a high degree the rapidity of the hydrolytic action, and this fact would point to the inference that the hydrolysis is promoted by $\mathrm{HCl}+\mathrm{H}_{2} \mathrm{O}$, and not by the hydrogen ions, unless some other predominant and preparatory reaction can be attributed to dehydrating agents like chlorhydric acid, sulphuric acid, and zinc chloride. The study of this hypothesis has been undertaken, but seems to demand an extended series of experiments before an opinion can be formed, and it is desired to give in this preliminary notice a description of experiments which establish a sharp distinction between catalysis in dilute and concentrated solutions. It is possible that the newly observed phenomena may be quite different from catalysis and may require another name, but the old one has been made to hide so many mysteries that it will serve to cover this one also, until a new theory of the reaction can be founded upon a larger number of experiments.

I will give the results of some 150 measurements in sealed tubes chiefly at $100^{\circ}$, and will leave aside a larger number of experiments which were made by passing steam through sulphuric acid solutions of sulphonic acids at different temperatures.

The work will be interrupted for a few months, and it is desired to reserve the field until the projects, which will be indicated for further experiments along the same line, can be executed and the data obtained for explanation, or at least for correct formulation of this interesting reaction.

\section{EXPERIMENTAL RESULTS.}

On heating in sealed tubes at $100^{\circ}$, the metaxylene-sulphonic acid ( $1: 3: 4$ ) gives an easily measurable rate of decomposition 
with chlorhydric acid of concentrations varying between +3 per cent. and I 3 per cent. $\mathrm{HCl}$ gas; and the intervals of time which it is necessary to heat in order to decompose Io per cent. of the sulphonic acid, vary between thirty minutes and more than one hundred hours, according to the strength of the acid. Benzene and toluenesulphonic acids do not react at this temperature, paraxylenesulphonic acid acts very slowly, and the sulphonic acids of the higher homologues of benzene act too rapidly at $100^{\circ}$, and, moreover, these acids are only partly soluble in strong chlorhydric acid even at $100^{\circ}$. For these reasons the first series of determinations was made with the metaxylenesulphonic acid, $\mathrm{C}_{8} \mathrm{H}_{3} \mathrm{SO}_{3} \mathrm{H}+2 \mathrm{H}_{2} \mathrm{O}$. The crystals of the acid can be kept for any length of time exposed to the air with only slight hygroscopic changes of weight.

A mode of preparation, which was found much more advantageous than the passage by the barium salt, consists in using directly the solution obtained by heating, during two hours at IOO, 2 parts of common sulphuric acid and I part hydrocarbon. The immediate product is added cautiously, to prevent heating, to common chlorhydric acid (containing about $3^{8}$ per cent. $\mathrm{HCl}$ ) cooled to zero or below. Paratoluenesulphonic acid, the common forms of metaxylene and pseudocumene sulphonic acids, and the sulphonic acids of paraxylene and mesitylene are nearly insoluble in strong cold chlorhydric acid, and the fine crystalline precipitate can easily be washed with pure cold chlorhydric acid with little loss until entirely free from sulphuric acid. Exposure for two days on a glass plate suffices to remove all traces of chlorhydric acid, and to leave the pure sulphonic acids crystallized with their normal proportions of water of crystallization. The crystalline powder so obtained can be dissolved in water and recrystallized without change of weight. Paratoluenesulphonic acid has I molectule of water of crystallization; the other acids named have 2 molecules. Paratoluenesulphonic acid so prepared melts at $102^{\circ}$; metaxylenesulphonic acid $\left(\mathrm{I}: 3: 4\right.$ ) at $59.8^{\circ}$; paraxylenesulphonic acid melts at $86^{\circ}$; pseudocumenesulphonic acid ( $1: 3: 4: 5$ ) at I $22^{\circ}$.

The Hydrolysis, $\mathrm{C}_{8} \mathrm{H}_{10} \mathrm{SO}_{3}+\mathrm{H}_{2} \mathrm{O}=\mathrm{H}_{2} \mathrm{SO}_{4}+\mathrm{C}_{8} \mathrm{H}_{10}$. -In each experiment a weighed quantity of the sulphonic acid was sealed with a weighed quantity of chlorhydric acid, or some other substance or acid as a catalysor, in a glass tube of about I cm. 
diameter, which had been calibrated with weighed amounts of the hydrocarbons, xylene, cumene, etc.

The determinations were made, after heating a definite period, by measuring the beight of the layer of hydrocarbon set free. Certain precautions were taken relative to the solubility of the hydrocarbon in the acid solution both hot and cold, and the time required for the complete separation of the dissolved hydrocarbon on cooling. A few control determinations of the stilphuric acid set free were also made, but in this preliminary notice it is not necessary to enter into the details of these operations, because even considerable errors of measurement and impurity of the sulphonic acids would not disguise the nature of the reaction, which it is designed to show.

A well determined and constant temperature was obtained by using the ebullition of pure substances, water and benzene, under atmospheric pressure. The tubes were always heated in contact with the liquid bath, and allowance was made for the time (about three minutes) required for a thermometer enclosed in a similar tube to take the temperatures of $79^{\circ}$ or $99^{\circ}$. If the test is made by plunging the glass tube, containing a thermometer and filled with liquid, in a metal tube heated by boiling water to a constant temperature but only containing air, the transfer of heat through the air layer to the glass tube is so slow that nearly an hour is required for the thermometer to reach $100^{\circ}$.

A. Experiments with Metaxylenesulphonic Acid and Chlorhydric Acid.-In the following experiments (Nos I-XIII), the temperature was $99.7^{\circ}-100^{\circ}$. The hours from the commencement of heating and the corresponding percentages of decomposition are given. The latter was usually determined by measuring the hydrocarbon set free in a tube which had been calibrated at the same place with known weights of the same hydrocarbon. It was usually necessary to wait some hours for the complete separation of the hydrocarbon which had dissolved at a high temperature in the acid liquid, but appeared to be almost completely separated in the cold, so that the readings became constant after intervals of an hour.

I. Io grams metaxylenesulphonic acid, $\mathrm{C}_{6} \mathrm{H}_{3} \mathrm{CH}_{3}$ (I) $\mathrm{CH}_{3}(3)$ $\mathrm{SO}_{3} \mathrm{H}(4)+2 \mathrm{H}_{2} \mathrm{O},+75$ grams chlorhydric acid ( IO per cent. $\mathrm{HCl}$ ). 


$\begin{array}{rccc}\text { Hours. } & \begin{array}{c}\text { Xylene. } \\ \text { Percent. }\end{array} & \text { Hours. } & \text { Xylene. } \\ \text { I6 } & 0.0 & 136 & 8.7 \\ 32 & 2.2 & 156 & 8.7 \\ 64 & 4.3 & 172 & 9.4 \\ 104 & 5.6 & 212 & 10.0 \\ 120 & 6.5 & & \end{array}$

The apparent retardation of the decomposition during the first sixteen hours is probably only due to the solubility in the acid mixture of the first fraction of xylene, about 0.04 gram. If this is the case, about I per cent. should be added to all the measures. The decomposition with a measurable rate of speed up to about Io per cent., and from that point a decomposition of only 0.6 per cent. in forty hours, seems to indicate the presence of an impurity, possibly $\mathrm{C}_{8} \mathrm{H}_{3} \mathrm{CH}_{3}$ (I) $\mathrm{SO}_{3} \mathrm{H}$ (2) $\mathrm{CH}_{3}$ (3), which decomposes more rapidly, while the pure acid, $\mathrm{C}_{8} \mathrm{H}_{3} \mathrm{CH}_{3}$ (I) $\mathrm{CH}_{8}$ (3) $\mathrm{SO}_{3} \mathrm{H}(4)$, which remains is not decomposed by ro per cent. chlorhydric acid solution.

II. Ten grams metaxylenesulphonic acid +75 grams chlorhydric acid ( $\mathrm{I} 3 . \mathrm{I}$ per cent. $\mathrm{HCl}$ ). 0.43 gram xylene was added before heating in order to saturate the acid liquid, the height of the layer of xylene was noted after shaking, and was subtracted from subsequent readings.

$\begin{array}{cccc}\text { Hours. } & \text { Xylene. } & \text { Hours. } & \begin{array}{c}\text { Xylene. } \\ \text { Per cent. }\end{array} \\ 16 & 1.9 & 136 & 10.2 \\ 32 & 2.4 & 152 & 12.0 \\ 48 & 4.2 & 172 & 13.8 \\ 64 & 5.4 & 188 & 15.7 \\ 88 & 7.9 & 204 & 17.4 \\ 104 & 9.0 & 220 & 18.7 \\ 120 & 10.2 & & \end{array}$

The series was terminated by the breaking of the tube.

III. Ten grams metaxylenesulphonic acid +70 grams chlorhydric acid ( 19 per cent. $\mathrm{HCl}$ ). No corrections were made for the solubility of xylene in the acid solution in this and in the subsequent experiments.

$\begin{array}{cccc}\text { Hours. } & \begin{array}{c}\text { Xylene. } \\ \text { Per cent. }\end{array} & \text { Hours. } & \begin{array}{c}\text { Xylene. } \\ \text { Per cent. }\end{array} \\ 4 & 1 . & 144 & 40.5 \\ 20 & 6.4 & 160 & 44.6 \\ 24 & 9.0 & 176 & 47.8 \\ 40 & 14.7 & 192 & 51.1 \\ 56 & 20.0 & 208 & 54.8 \\ 72 & 21.7 & 224 & 58.1 \\ 88 & 25.7 & 240 & 61.0 \\ 104 & 30.7 & 256 & 63.8 \\ 128 & 36.4 & 272 & 66.3\end{array}$


IV. Ten grams metaxylenesulphonic acid +30 grams chlorhydric acid ( 10.3 per cent. $\mathrm{HCl}$ ) +8.75 grams sulphuric acid.

$\begin{array}{cccc}\text { Hours. } & \begin{array}{c}\text { Xylene. } \\ \text { Per cent. }\end{array} & \text { Hours. } & \begin{array}{c}\text { Xylene. } \\ \text { Per cent. }\end{array} \\ 4 & \text { I.0 } & 96 & 31.8 \\ 8 & 2.5 & 112 & 36.2 \\ 12 & 4.0 & 133 & 40.8 \\ 16 & 7.0 & 155 & 46.3 \\ 32 & 12.6 & 175 & 51.9 \\ 48 & 17.6 & 19 I & 55.4 \\ 64 & 23.1 & 23 I & 63.9 \\ 80 & 27.7 & 279 & 70.4\end{array}$

V. Ten grams metaxylenesulphonic acid + 93 grams chlorhydric acid (ig per cent. $\mathrm{HCl}$ ) +37.5 grams zinc chloride.

$\begin{array}{cccc}\text { Hours. } & \begin{array}{c}\text { Xylene. } \\ \text { Per cent. }\end{array} & \begin{array}{c}\text { Hours. } \\ \text { Pylene. }\end{array} \\ 4 & 3.0 & 24 & 30.9 \\ 8 & 13.4 & 28 & 31.1 \\ \text { I2 } & 16.0 & 32 & 34.8 \\ \text { I6 } & 22.0 & 36 & 38.8 \\ 20 & 26.0 & 40 & 42.3\end{array}$

VI. Twenty grams metaxylenesulphonic acid +90 gramschlorhydric acid ( 25 per cent. $\mathrm{HCl}$ ).

$\begin{array}{cccc}\text { Hours. } & \begin{array}{c}\text { Xylene. } \\ \text { Per cent. }\end{array} & \begin{array}{c}\text { Hylene. } \\ \text { Per cent. }\end{array} \\ 4 & 3.6 & \mathbf{5 2} & \mathbf{5 5 . 2} \\ 8 & 10.0 & 56 & 58.0 \\ \text { I2 } & 16.0 & 60 & 60.9 \\ 16 & 20.3 & 64 & 64.8 \\ 20 & 27.1 & 68 & 67.7 \\ 24 & 32.0 & 72 & 69.8 \\ 28 & 35.6 & 88 & 77.7 \\ 32 & 39.2 & 104 & 84.1 \\ 36 & 44.9 & 120 & 86.9 \\ 40 & 46.3 & 136 & 90.1 \\ 44 & 48.1 & 152 & 91.5 \\ 48 & 52.0 & & \end{array}$

VII. Ten grams metaxylenesulphonic acid +5 I 5 grams chlorhydric acid ( 25 per cent. $\mathrm{HCl}$ ).

$\begin{array}{cc}\text { Hours. } & \text { Xylene. } \\ 4 & \text { Per cent. } \\ 16 & 2 \\ 20 & 22 \\ & 29\end{array}$

A large bulb with a narrow neck of very thick glass was used. The calibration of the somewhat conical neck was less exact, and the readings were more uncertain than in a tube. 
VIII. Twenty grams metaxylenesulphonic acid - 70 grams chlorhydric acid (3I.4 per cent. HCl).

$\begin{array}{cccc}\text { Hours. } & \begin{array}{c}\text { Xylene. } \\ \text { Per cent. }\end{array} & \text { Hours. } & \text { Xylene. } \\ 4 & 14.2 & 28 & 83.1 \\ 8 & 29.7 & 44 & 92.0 \\ \text { I2 } & 47.6 & 60 & 96.1 \\ 16 & 57.9 & 76 & 95.6 \\ 20 & 68.3 & 92 & 95.9 \\ 24 & 76.9 & & \end{array}$

IX. Ten grams metaxylenesulphonic acid +550 grams chlorhydric acid ( $3 \mathrm{I} .4$ per cent. $\mathrm{HCl}$ ).

$\begin{array}{cccc}\text { Hours. } & \text { Xylene. } & \text { Hours. } & \text { Xylene. } \\ \text { I } & \text { Per cent. } & \text { Per cent. } \\ 2 & 6.3 & \text { IO } & 35.2 \\ 6 & 9.4 & \text { I } & 44.8 \\ & 20.9 & \text { I8 } & 60.0\end{array}$

$\mathrm{X}$. Twenty grams metaxylenesulphonic acid +7 ograms chlorhydric acid $(38.4$ per cent. $\mathrm{HCl})$.

$\begin{array}{cccc}\text { Hours. } & \begin{array}{c}\text { Xylere. } \\ \text { Pet cent. }\end{array} & \text { Hours. } & \text { xylene. } \\ 4 & 34.9 & 48 & 91.8 \\ 8 & 67.7 & 64 & 93.0 \\ \text { I2 } & 83.7 & 80 & 94.5 \\ \text { I6 } & 88.7 & & \end{array}$

$\mathrm{XI}$. Ten grams metaxylenesulphonic acid +38 grams chlorhydric acid ( 38.4 per cent. $\mathrm{HCl})$.

\begin{tabular}{|c|c|c|c|}
\hline Hours. & $\begin{array}{l}\text { Xylene. } \\
\text { Per cent. }\end{array}$ & Hours. & $\begin{array}{l}\text { Xylene, } \\
\text { Per cent. }\end{array}$ \\
\hline$\frac{1}{4}$ & 0 & 52 & 48.9 \\
\hline & 3 & $6 \frac{1}{2}$ & 56.5 \\
\hline & 5.7 & $7 \frac{1}{\frac{1}{2}}$ & 60.8 \\
\hline I & 8.4 & $8 \frac{1}{2}$ & 66.6 \\
\hline $1 \frac{1}{2}$ & 14.0 & 9 & 70.6 \\
\hline 2 & 18.6 & $10 \frac{1}{2}$ & 72.1 \\
\hline 27 & 23.5 & II $\frac{1}{2}$ & 74.7 \\
\hline 3 & 28.5 & 13 & 79.7 \\
\hline 4 & 37.2 & 15 & 81.0 \\
\hline $4 \frac{1}{3}$ & 41.0 & I $7 \frac{1}{2}$ & 82.0 \\
\hline
\end{tabular}

XII. Ten grams metaxylenesulphonic acid +39 grams chlorhydric acid ( 43 per cent. $\mathrm{HCl}$ ).

$\begin{array}{cccc}\text { Hours. } & \begin{array}{c}\text { Xylene. } \\ \text { Per ceut. }\end{array} & \text { Hours. } & \begin{array}{c}\text { Xylene. } \\ \text { Per cent }\end{array} \\ 2 & 38.2 & 9 & 90.7 \\ 4 & 68.6 & 10 & 91.0 \\ 5 & 77.2 & 14 & 92.8 \\ 6 & 86.0 & 18 & 94.2 \\ 7 & 89.5 & 22 & 97.3 \\ 8 & 90.4 & 38 & 97.7\end{array}$


XIII. Ten grams metaxylenesulphonic acid +38 grams chlorhydric acid ( 38.4 per cent. $\mathrm{HCl})+19$ grams $\mathrm{ZnCl}_{2}$.

$\begin{array}{cccc}\text { Hours. } & \begin{array}{c}\text { Xylene. } \\ \text { Percent. }\end{array} & \text { Hours. } & \begin{array}{c}\text { Xylene. } \\ \text { Per cent. }\end{array} \\ \text { I } & 28.1 & 6 & 92.2 \\ 2 & 55.0 & \text { Io } & 96.4 \\ 3 & 75.9 & \text { I4 } & 97.5 \\ 4 & 86.1 & \text { I } & 99.8 \\ 5 & 90.3 & 34 & 99.4\end{array}$

XIV. Temperature $80.2^{\circ}$. -Ten grams metaxylenesulphonic acid $+3^{6}$ grams chlorhydric acid $(38.4$ per cent. $\mathrm{HCl})+$ I 8 grams zinc chloride.

$\begin{array}{cccc}\text { Hours. } & \text { Xylene. } & \text { Hours. } & \text { Xylene. } \\ 4 & \text { Per cent. } & 20 & 49.6 \\ 8 & 6.0 & 24 & 57.5 \\ \text { I2 } & \text { I5.6 } & 28 & 65.3 \\ \text { I6 } & 27.9 & 32 & 72.2\end{array}$

B. Experiments with Metaxylenesulphonic Acid Heated with Sulphuric Acid at $100^{\circ}$.-

$\mathrm{XV}$. Ten grams metaxylenesulphonic acid +35 grams dilute sulphuric acid (25 per cent. $\mathrm{H}_{2} \mathrm{SO}_{4}$ ) were heated twenty hours at $100^{\circ}$. There was no sign of separation of xylene.

XVI. Ten grams metaxylenesulphonic acid + I 22 grams dilute sulphuric acid ( 50 per cent. $\mathrm{H}_{2} \mathrm{SO}_{4}$ ).

$\begin{array}{cccc}\text { Hours. } & \begin{array}{c}\text { Xylene. } \\ \text { Per cent. }\end{array} & \begin{array}{c}\text { Xylene. } \\ \text { Per cent. }\end{array} \\ 4 & 4.2 & 56 & 69.6 \\ 8 & 13.9 & 60 & 71.4 \\ \text { I2 } & 21.2 & 64 & 74.4 \\ 16 & 27.8 & 68 & 76.3 \\ 20 & 34.5 & 72 & 78.1 \\ 24 & 40.6 & 76 & 79.3 \\ 28 & 44.2 & 80 & 81.7 \\ 32 & 47.8 & 96 & 85.4 \\ 36 & 52.7 & \text { II } & 86.0 \\ 40 & 56.3 & 128 & 87.2 \\ 44 & 59.3 & 144 & 88.4 \\ 48 & 64.2 & 160 & 88.4 \\ 52 & 66.6 & 176 & 88.4\end{array}$

XVII. Ten grams metaxylenesulphonic acid + dilute sulphuric acid ( 75 per cent. $\mathrm{H}_{2} \mathrm{SO}_{4}$ ).

Soon after heating, the well-known phenomenon took place between the diluted sulphuric acid and the sulphonic acid: a lighter layer of a viscous liquid rose to the top, and this was 
covered by a smaller layer of xylene. The viscous layer which separated contained 5.5 per cent. of dissolved xylene, and the remainder had nearly the composition $\mathrm{H}_{2} \mathrm{SO}_{4}+2 \mathrm{H}_{2} \mathrm{O}$ (33 per cent. $)+\mathrm{C}_{8} \mathrm{H}_{10} \mathrm{SO}_{3}+2 \mathrm{H}_{2} \mathrm{O}$ (67 per cent.). It is more probable, however, that most of the water should be regarded as combined with sulphuric acid, and the greater part of the metaxylenesulphonic acid must be anhydrous on account of its power of dissolving xylene. This view is confirmed by the fact that the crystalline hydrated sulphonic acid dissolves on gently warming in sulphuric acid, diluted with enough water to make 75 per cent. $\mathrm{H}_{2} \mathrm{SO}_{4}$ and then an acid separates later on heating, giving the upper viscous layer.

These experiments suggest the idea that all dehydrating agents may bring the crystalline hydrated sulphonic acids into an anhydrous state, and that the anhydrous form may exist in solution, and perhaps be more susceptible of hydrolysis than the hydrated acids. This hypothesis will be investigated.

C. Metaxylenesulphonic Acid Heated to $100^{\circ}$ with Nitric Acid.-

XVIII. Ten grams metaxylenesulphonic acid + common nitric acid, diluted with an equal weight of water, were heated three hours at $100^{\circ}$ in a sealed tube. There was no sign of xylene, and only traces of insoluble nitro derivatives. The pressure of gas due to oxidation was not very strong.

Thus nitric acid has no action favoring hydrolysis to be compared to that of a molecular equivalent of chlorhydric or sulphuric acid.

THE RELATION BETWEEN CONCENTRATION OF THE ACID SOLUTIONS AND THE RAPIDITY OF THE HYDROLYSIS.

Curves were plotted of all these series of experiments, and the following table gives the time required in each case to decompose 5 , 10, 15, etc., per cent. of the sulphonic acids.

In experiments II to XVI the first vertical column of the above table gives the percentages by weight of $\mathrm{HCl}$ gas in the chlorhydric acid solution; the second column gives the weights of acid solution to which in each case 10 grams of crystallized sulphonic acid were added, and the third vertical column gives for experiment IV a weight of $\mathrm{H}_{2} \mathrm{SO}_{4}$ added to the solution, while for experiments $\mathrm{V}, \mathrm{XIII}$, and XVI weights of $\mathrm{ZnCl}_{2}$ were added.

The next 18 vertical columns give the hours and decimal frac- 


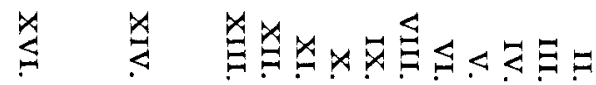

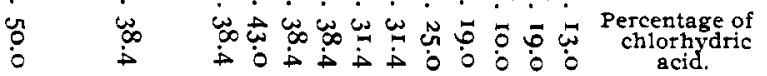

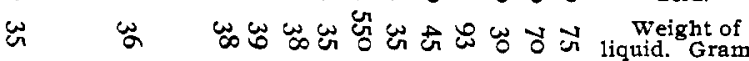

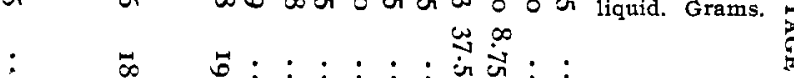

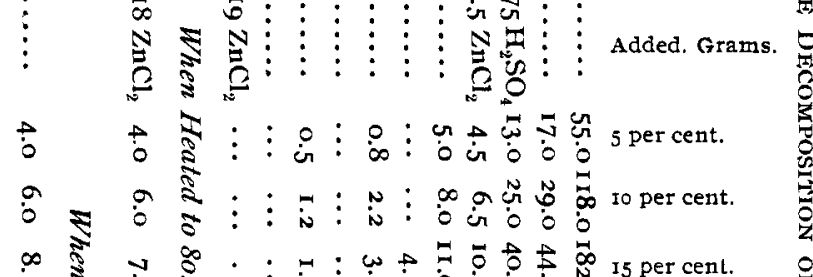

is

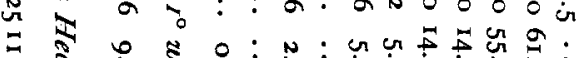

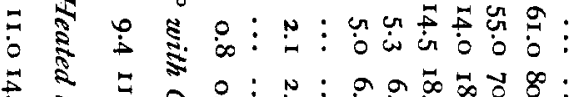

$\stackrel{+}{\circ}$

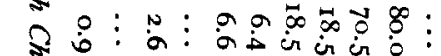

25 per cent.

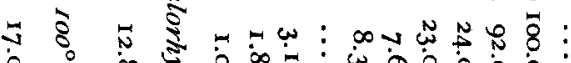

io

in

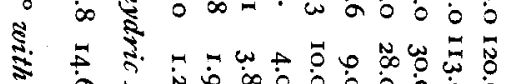

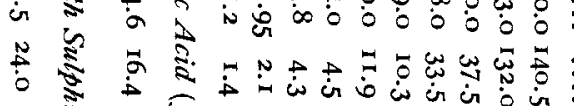

35 per cent.

40 per cent.

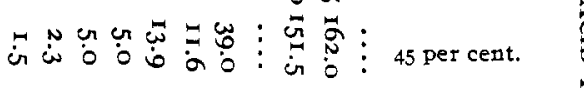

$\because$ 少

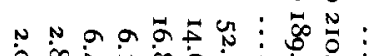

in

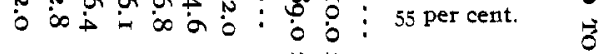

N

م

$\rightarrow$ - in in in

65 per cent.

$\exists$

$N \overrightarrow{0} \infty:$ :

告

$\frac{0}{0}$

i

$0 \div 0$ : $\omega^{N}::$ : 75 per cent.

w en 5 : N N : : : : 80 per cent.

$\rightarrow N \omega \infty$. $\infty$ :

$\vdots \vdots \vdots \vdots: \oplus \stackrel{0}{\vdots}: \vdots:$ : 85 per cent.

赵

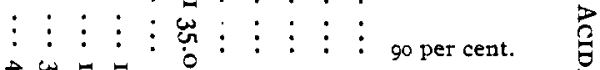

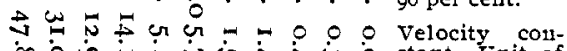

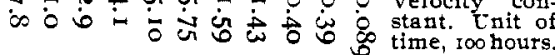


tions of an hour required to decompose 5, IO, 15, etc., per cent. of the sulphonic acid.

The last column gives the relocity constants calculated, not from the figures of the table, but from the means of the constants given by each experimental measure, rejecting those of less than Io and more than 80 per cent. decomposition, because at the two extremities the results are less accurate.

A rery remarkable relation appears between the relocity constants and the concentration of the chlorhydric acid which promotes the action (as a catalysor?).

For the percentages of $\mathrm{HCl}$ between $\mathrm{I} 3$ and $3^{\mathrm{I}}$ the velocity increases fourfold for each successive increment of 6 per cent. $\mathrm{HCl}$. The rate appears to be less rapid for higher percentages, but the upper limit of the law may perhaps be extended by more careful measures. Unpublished experiments confirm this relation for other sulphonic acids and extend it to lower percentages of $\mathrm{HCl}$.

Mathematically stated, the relation is expressed by the formula: the logarithm of the relocity constant is a linear function of the percentage concentration of chlorhydric acid.

Since the sulphonic acids have nearly as strong a chemical affinity as chlorhydric acid, it was thought that they might catalyze themselves, and the decomposition might be related to the concentration. Only two experiments have been made, but they serve to confirm this idea:

I. Five grams metaxylenesulphonic acid were dissolved in 2.5 grams of water, and were heated at $100^{\circ}$ for forty hours. The sulphuric acid set free was 1.9 per cent. of the amount corresponding to complete decomposition. No xylene was visible in the tube, but it separated out on diluting with water.

2. Five grams of metaxylenesulphonic acid were dissolved in roo grams water and heated to $100^{\circ}$ for forty hours. The sulphuric acid set free was only 0.1 per cent. Thus concentration in these experiments gives rise to a rapidly increasing rate of decomposition.

With metaxylenesulphonic acid a change of position of the $\mathrm{SO}_{3} \mathrm{H}$ group, if such change can be brought about catalytically, would complicate the reaction, since the susceptibility to decomposition is greatly increased, when the $\mathrm{SO}_{3} \mathrm{H}$ group is placed between the two side-chains.

The series of experiments will be extended to other tempera- 
tures and the more tedious, but likewise more accurate, method of weighing the sulphuric acid set free instead of measuring the amount of hydrocarbon will be used.

If we attempt to estimate the differences and the similarities in the modes of catalytic action of strong acids in concentrated or in weak solutions, it will be convenient to do so under the headings of Ostwald's definition of catalysis.

I. Reactions Which Are Accelerated or Retarded by Catalysis Take Place Also without a Catalysor. - Experiments are evidently impossible with substances which take years for the transformation of I per cent., and conclusions can usually only be drawn from the form of reaction curves of measurable velocities, but it appears probable that the regularity of the decomposition of sulphonic acids without by-products will make it possible to obtain useful observations near the border line, where the action is almost imperceptible.

2. Reactions in Opposite Directions Leading to an Equilibrium Must Be Equally Infuenced by Catalysis. - The hydrolysis of sulphonic acids in presence of sulphuric acid and water would belong under this rule if the reaction were reversible, but this is probably not the case since the synthesis is direct, while the decomposition is indirect by infuence of $\mathrm{H}_{2} \mathrm{SO}_{4}$ (catalysis?). The data for 50 per cent. sulphuric acid given in the preceding table show that the limit of the action is very near complete decomposition, 88 per cent., while experiments made by heating xylene with sulphuric acid of 50 per cent. concentration to $100^{\circ}$ proved that the reverse action does not take place perceptibly.

Even the action of a 75 per cent. sulphuric acid solution on xylene is an exceedingly slow one and stops when only a few per cent. of the xylene are transformed into the sulphonic acid. The hydrolysis of sulphonic acids by means of chlorhydric acid tends to complete decomposition, nor can any evidence be obtained of an inverse reaction.

3. The Catalytic InAuence is Nearly Proportional to the Concentration of the Catalysor. - The chief object of this paper is to show that this rule does not apply to the case of concentrated acids, and that here the facts are directly opposed to the assumption that hydrolysis is caused by hydrogen ions. In the experiments cited the relation between concentration of acid and effect rises like the tension of a gas partially combined with water and the 
effect of high concentration in aqueous solution of chlorhydric acid alone, and especially with addition of zinc chloride, recalls the activity imparted to gases condensed on platinum or palladium. Ostwald discusses the action of these metals under the same heading as catalysis attributed to the ions of hydrogen, iron, manganese, etc., and $\mathrm{OH}$ ions, and also places ferments and enzymes beside them, saying there is no great doubt that the laws governing the action of these bodies are not essentially different from those of inorganic catalysors.

Taking these definitions together, they apply in very few points to the case of hydrolysis by concentrated acids.

The question of ionic dissociation presents new aspects in this case. Usually the compounds subjected to catalysis have been like sugar and esters, incapable of any marked degree of dissociation in aqueous solution. The sulphonic acids, on the contrary, are dissociated to nearly the same degree as the strongest acids, when in dilute solution, and although very little is known of the dissociation of strong acids in concentrated solution, it well may be considerable. If hydrolysis only takes place upon undissociated molecules, then the increased rapidity due to high concentration of the acid solution and to addition of zinc chloride may be ascribed to the prevention of the dissociation of the catalyzed body, while that of the catalysor subsists to a certain degree.

Experiments at different temperatures and with more sensitive bodies like mesitylenesulphonic acid which acts at low temperatures and with weaker acids, may throw some light upon this subject.

The usefulness is evident of a minute study of the difference of behavior of the sulphonic acids, for it may obviousiy lead to methods of separation of the hydrocarbons and the acids. Several authors have described such methods for the separation of metaand paraxylene, and $I$ have found during this series of experiments that mesitylenesulphonic acid, when heated to $80^{\circ}$ for fifteen minutes with $3^{8}$ per cent. chlorhydric acid, is almost wholly decomposed, while pseudocumenesulphonic acid, heated under the same circumstances, gives no sign of the separation of pseudocumene after five hours. Armstrong has used this difference of action to separate the two hydrocarbons by heating their sulphonic acids with chlorhydric acid at $100^{\circ}$, but the statement attributed to him in Beilstein II, 29, is incorrect; namely, that 
pseudocumenesulphonic acid is not decomposed by heating for one hour with strong chlorhydric acid at $100^{\circ}$. There is diffculty in getting the rate for the first hour, because the pseudocumenesulphonic acid does not dissolve rapidly in strong chlorhydric acid at $100^{\circ}$, but the following determinations show the rate for subsequent hours :

Ten grams pseudocumenesulphonic acid, heated to $100^{\circ}$, with 35 grams chlorhydric acid ( 38.4 per cent. $\mathrm{HCl}$ ), gave the following results :

$\begin{array}{cccc}\text { Hours. } & \begin{array}{c}\text { Pseudocumene. } \\ \text { Per cent. }\end{array} & \text { Hours. } & \begin{array}{c}\text { Pseudocumene. } \\ \text { Per cent. }\end{array} \\ 1 \frac{1}{2} & 24.7 & 6 \frac{1}{2} & 95.9 \\ 2 \frac{1}{2} & 42.3 & 7 \frac{1}{2} & 101.6 \\ 3 \frac{1}{2} & 61.8 & 8 \frac{1}{2} & 103.8 \\ 4 \frac{1}{2} & 76.6 & 9 \frac{1}{2} & 100.3 \\ 5 \frac{1}{2} & 90.5 & 10 \frac{1}{2} & 100.3\end{array}$

The impossible results, I03.8 per cent., etc., may be due to the fact that a small anount of anhydrous sulphonic acid separates out and dissolves in the layer of hydrocarbon and is only slowly decomposed. All the results are too high for the same reason and a similar error, but a very sinall one, attaches to the preceding experiments with xylene. The fact that pseudocumenesulphonic acid loses a little water on long standing may also account for the above result.

Armstrong's observations were undoubtedly exact, but he is misquoted by Beilstein. He really states that an oily layer is formed by adding water to the immediate product of the action of sulphuric acid upon pseudocumene and this oil, added to an equal volume of common chlorhydric acid, is not decomposed by heating one hour to $100^{\circ}$. No strength of acid is given, but the oily layer so described contains anhydrous pseudocumenesulphonic acid in solution in aqueous sulphuric acid, and the water present probably suffices to dilute the acids to the point where no perceptible decomposition takes place during one hour at $100^{\circ}$.

The name catalysis has been used after much hesitation, and it is only meant to imply that the rapidity of the action does not seem to be determined by the ordinary chemical forces of the bodies undergoing change, but rather that these forces are set in action in a peculiar way by an outside agent.

MassachusetTs INSTItUTE of

TECHNOLOGY, BOSTON,

February 26,1901 .

1 Ber. d. chem. Ges., 11, 1697. 